\title{
Strengthening the Creative Transformational Leadership of Primary School Teachers
}

\author{
Yadapak Kallapadee $^{1}$, Kowat Tesaputa ${ }^{2} \&$ Kanokorn Somprach ${ }^{2}$ \\ ${ }^{1}$ Faculty of Education, Mahasarakham University, Thailand \\ ${ }^{2}$ Faculty of Education, Khon Kaen University, Thailand \\ Correspondence: Yadapak Kallapadee, Faculty of Education, Mahasarakham University, Mahasarakham \\ Province 44000, Thailand. E-mail: yadapak.kall@gmail.com
}

Received: September 28, 2016

Accepted: November 2, 2016

Online Published: March 30, 2017

doi:10.5539/ies.v10n4p179

URL: https://doi.org/10.5539/ies.v10n4p179

\begin{abstract}
This research and development aimed to: 1) study the components and indicators of creative transformational leadership of primary school teachers; 2) study the existing situation, and the desirable situation of creative transformational leadership of primary school teachers in the northeastern region of Thailand; 3) develop a program to strengthen creative transformational leadership of primary school teachers; 4) study the results of implementing the strengthening of the creative transformational leadership program of primary school teachers. The research instruments are comprised of: 1) a form for evaluation components and indicators of creative transformational leadership; 2) a questionnaire for the existing situation and the desirable situation; 3 ) a form for the assessment of the program to strengthen the creative transformational leadership of primary school teachers; 4) a form for evaluating the results of implementing creative transformational leadership; 5) a test of creative transformational leadership. The research found that: The creative transformational leadership of primary school teachers has 5 elements and 16 indicators, including 1) the vision, 2) the intellectual stimulation 3) creativity, 4) inspirational motivation, 5) flexibility. The results of the study of the existing situation and the desirable situation of creative transformational leadership of primary school teachers showed at practice level every dimension and at overall were high. The study result of how to strengthen creative transformational leadership indicates coaching and mentoring levels were at high. Developed programs to strengthen creative transformational leadership of primary school teachers consisted of 5 modules: 1) the vision which covers three indicators, namely, picture mind, challenge and goal, 2) the intellectual stimulation which covers three indicators, namely, promotion of wisdom use, rationality and the ability to solve problems, 3) creativity which covers four indicators, namely, the initiative idea, the flexibility of thinking, fluency of and the quality of thinking, 4) inspirational motivation which covers three indicators, namely, confidence, concentration in action, hope for success, 5) flexibility of thought which covers three indicators, namely, adaptation according to the situation, adaptation to problem solution and action ability in several dimensions. The second program was guideline-applied coaching and mentoring processes. The results of the study found significant difference between before and after use of the strengthening in that the level after use was higher than before using every module ( $\mathrm{p}$-value $<0.05$ ).
\end{abstract}

Keywords: strengthening creative transformational leadership, primary school teachers

\section{Introduction}

The Ministry of Education has focused on reforming education and learning systems in four main pillars, including: 1) the development of a new Thai generation by adjusting the paradigm for learning so that students can develop their desirable characteristics, 2) the development of a new generation of teachers, 3) the development of educational places and learning sources in a new era, and 4) develop new management by adjusting the effective administrative management system to provide the flexibility of increasing educational opportunities and also promoting the participation of all sectors of education management (Office of the Education Council, 2009).

To get the continuity and sustainability of educational institution development has required dedication and concentration on the subject of teacher enquiry, collaboration, shared leadership, and collective responsibility. It is desired to make teachers clearly understand common values, beliefs and performance accordingly. The construction of a culture and behavior in schools needs to focus on the development of the norms, values, beliefs 
and assumptions of the school. It must pay attention to students and support continuous professional development. The developmental goal of educational institutions is positive cultural and process change. Deep-rooted changes are necessary to sustain the development of institutions (Harris \& Lambert, 2003).

Nowadays we face complexities when teaching. It forces the requirement of high standards of teaching practice. Teachers are considered as primary professionals and being a core sector to change a knowledge-based society. Without teachers and their high potential, society will be shaped into a future different from the present or become an undesirable society.

The teacher plays a key role in the creation and development of the youth who are the future of the nation. This is a goal of education, with the requirement for critical- thinking skills, knowledge initiative, learning-oriented lifestyle and living with happiness. Therefore, it is a time to encourage educational authorities to think more deeply about the learning process, the body of knowledge and professional status of teachers who are the main individuals conducting teaching in current society. Teachers should be supported properly in the learning process in order for them to avail themselves to students in ways that allow those students to learn properly. This is an important part of responsibilities of leadership and is also one of the key elements of the professional learning experience among teachers (Goodson \& Hargreaves, 2005).

Leadership capability implies the mental, knowledge and skill elements when broadly involved in missions of leadership for learning and working together. This brings sustainable development. Leadership capability is the concept to build leadership capacity for school development which focuses on developing the leadership capacity of the personnel involved in sustainable development. In general, the basic concept is that leadership should not be limited to official position but also be distributed to the personnel in place so that the concept of distributed leadership work-sharing is realized fully. It is necessary also to recognize the importance and the need for further development of the school as a learning organization. The people in the organization, everyone has to learn continuously to build self-knowledge from learning together and exchanging ideas with others based on a constructivism concept.

It also helps building a good relationship among staff which will lead to a working collaboration and the development of sustainable education (Harris \& Lambert, 2003). With the focus on collaboration for a common goal, leadership will evolve naturally and pass from one person to another if the situation changes (Gronn, 2008). The leader is also facing new situations unlike those encountered in the past. Therefore, leaders must adapt themselves to the new changes and take steps to initiate adaptations for the whole system. This adaptation is the restructure of organization to achieve organizational effectiveness. Meanwhile, it should improve the capacity of members in the organization to achieve individual effectiveness (Certo, 2006).

The leaders in the new era must decentralize their authority and leadership to their organization. (Spillane, 2006) To achieve goals, one successful key of a leader is the ability to change and to face challenges with new approaches (Chareonwongsak, 2007). Leaders construct social development. There are many kinds of leadership. Leadership study can be done in many ways, such as is characteristic of leadership, leadership in behavior and leadership in situational orientation. However, three approaches are not enough to understand leadership in order to determine direction and goals clearly. To assure that society proceeds well in terms of creativity and value, there is needed collaborative agreement, honesty, responsibility, and common good-will (Hedberg, 1981; Greenberg \& Baron, 2002).

The study of leadership should be considered in-depth and in broad detail. The new leader requires thought and ideas beyond the normal pattern. Creative leadership as a model for development is research inclusive of concept, patterns and processes (Sinlarat, 2010). We can predict successful transformational leadership by the intelligence, emotions and thoughts of the leader. However, leadership change may occur for several predictable reasons, including organizational atmosphere and satisfaction of organization members (Mccutcheon, 2005).

Transformational leadership is positively correlated with the quality of work. It prominently influences organization members, motivates members to trust, show loyalty and have confidence in the organization. Exemplary leaders engender conceptual and behavioral inspiration and willingness to work. There is created the recognition and awareness of the importance and danger of the problems faced by the organization. The recognition of the individual member and the value of his/her contributions to the organization will stimulate creativity and innovation within that organization (Dunham-Tayor, 2000).

Currently, the major problem of primary teachers who work for the Office of the Basic Education Commission is lack of leadership skills, collaboration, co-leadership, and self-confidence. As a result, teachers cannot make decisions well when working, have no definite opinions, and engender little inspiration. Situations such as these influence teachers' performance and impact on the academic achievement of students. 
For these reasons, we were convinced we must develop a program to strengthen the creative transformative leadership of primary school teachers, as this would benefit the development of paradigm, human resource, and quality of work and achieve the teaching profession standard. Teachers' transformational leadership would be creative, with efficiency and effectiveness, and result in contributions to ongoing development and sustainability.

\section{Objectives}

1) To study the elements and indicators of creative transformational leadership of primary school teachers.

2) To study the existing situation, and the desirable situation of the creative transformational leadership of primary school teachers in the northeastern region of Thailand.

3) To develop a program to strengthen creative transformational leadership of primary school teachers.

4) To study the results of the implementation of program-strengthening creative transformational leadership of primary school teachers.

\section{Methodology}

Research and development was conducted in four phases.

Phase 1: studied the elements and indicators of creative transformational leadership of primary school teachers

1) Reviewed concept and theory related to the creative transformational leadership of primary school teachers.

2) Synthetic components and indicators of transformational leadership, creativity of primary school teachers.

3) Seven experts reviewed the elements and indicators of creative transformational leadership of primary school teachers.

4) The research instrument was a form for assessment of the elements and indicators of transformational leadership of creative teachers. We used a rating scale following Likert's concept in three levels: consistent uncertain and inconsistent. The question-items were confirmed consistency of the content and operation definition. It was reviewed by experts, after which the language and content validity were fixed.

Phase 2: Studied the existing situation, and the desirable situation of creative transformational leadership of primary school teachers.

1) Population and sample: The population in this study was 129,599 primary school teachers who work for the Office of the Basic Education Commission in the northeastern region of Thailand. We calculated the sample size by using the table of Krejcie \& Morgan, 384 persons. Stratified random sampling was applied, We selected 20 provinces and 19 teachers from each province. Then, each province applied simple random sampling to select one area of primary education. The size of the school is stratified and used school as a unit in random order. There is conducted a random stratified approach according to randomization, then there is applied simple random sampling to select 384 schools by the size of the school. Each school has a designated teacher as key informant.

2) Research instrument: the questionnaire was used to collect data pertaining to the existing situation, as well as the desirable situation in terms of how to strengthen creative transformational leadership of primary school teachers. It is composed of three sections: 1) Checklist question included gender, age, education, and work experience 2) Questions asked about the current and desirable situation measured by the rating scale of Likert's concept as divided into 5 scale-segments: always practices, often practices, sometimes practices, never practices, and 3) The opened question.

Phase 3: Develop a program to strengthen creative transformational leadership of primary school teachers

1) Drafted program: this is a program to strengthen creative transformational leadership of primary school teachers. The program consists of 5 modules: module 1 vision, module 2 intellectual stimulation, module 3 creativity, module 4 inspirational motivation, and module 5 flexibility.

2) Research instruments: assess the suitability and feasibility of enhancing the creative leadership of teachers

3) Seven experts assessed the suitability and feasibility of the program and guideline for strengthening creative transformational leadership.

4) There was developed a guideline for applied coaching and mentoring process on how to strengthen teachers on creative transformational leadership. Seven experts reviewed and confirmed this guideline.

Phase 4: Studied the effects of a development program strengthening creative transformational leadership of primary school teachers. 
1) Conducted strengthening program with primary school teachers selected by purposive sampling.

2) Pre-post tested the result of program use among 17 teachers.

3) Conducted satisfaction assessment of 17 teachers who used the strengthening program.

4) Research instruments of: 1) Evaluation of transformational leadership for creative teachers. 2) Test your knowledge of transformational leadership for creative teachers and 3) Assess the level of satisfaction with the program for strengthening the leadership of creative teachers.

\section{Results}

1) The synthesized result showed 5 elements and 16 indicators and of creative transformational leadership of primary school teachers; vision elements had 5 indicators, intellectual stimulation elements had 3 indicators, creative elements had 4 indicators, inspirational motivation elements had 3 indicators, and flexibility elements had 3 indicators.

2) The results of the study of the existing situation and desirable situation for creative transformational leadership of primary school teachers showed at practice level in every dimension and was high at overall (Table 1). Therefore, the teachers or interested persons should develop their own leadership at the highest level.

Table 1. Means and standard deviation of existing and desirable situation of creative transformational leadership of primary teachers

\begin{tabular}{lcccccc}
\hline & \multicolumn{3}{c}{ Current situation } & \multicolumn{3}{c}{ Desirable situation } \\
\cline { 2 - 7 } Elements & $\bar{X}$ & S.D & $\begin{array}{c}\text { Practical } \\
\text { level }\end{array}$ & $\bar{X}$ & S.D & $\begin{array}{c}\text { Practical } \\
\text { level }\end{array}$ \\
\hline 1. Vision & 3.59 & 0.91 & High & 4.09 & 0.90 & High \\
2. Intellectual stimulation & 3.81 & 0.86 & High & 4.30 & 0.75 & High \\
3. Creativity & 3.59 & 0.86 & High & 4.28 & 0.73 & High \\
4. Inspirational motivation & 3.70 & 0.92 & High & 4.27 & 0.78 & High \\
5. Flexibility & 3.83 & 0.84 & High & 4.30 & 0.75 & High \\
\hline Total & 3.70 & 0.87 & High & 4.25 & 0.78 & High \\
\hline
\end{tabular}

In existing situation of creative transformational leadership of primary school teachers, considered by items, it is found that the supervision coaching technique was at high level $(=3.56)$, mentoring technique was at high level $(\bar{X}=3.59)$. Meanwhile, the desirable situation showed high level for supervision coaching technique $(\bar{X}=4.04)$, mentoring technique $(\bar{X}=4.01)$

3) The result of designed programs to strengthen creative transformational leadership of primary school teachers showing in three dimensions. The first dimension was leadership development and consisted of 5 modules: module 1 vision, module 2 intellectual stimulation, module 3 creativity, module 4 inspirational motivation, and module 5 flexibility. The second dimension was strengthening and consisted of teaching and being a mentor. The third was evaluation after development and consisted of 1) five guidelines for strengthening the creative transformational leadership and 2) guideline-applied coaching and mentoring process with respect to strengthening teachers creative transformational leadership. (Figure 1) 


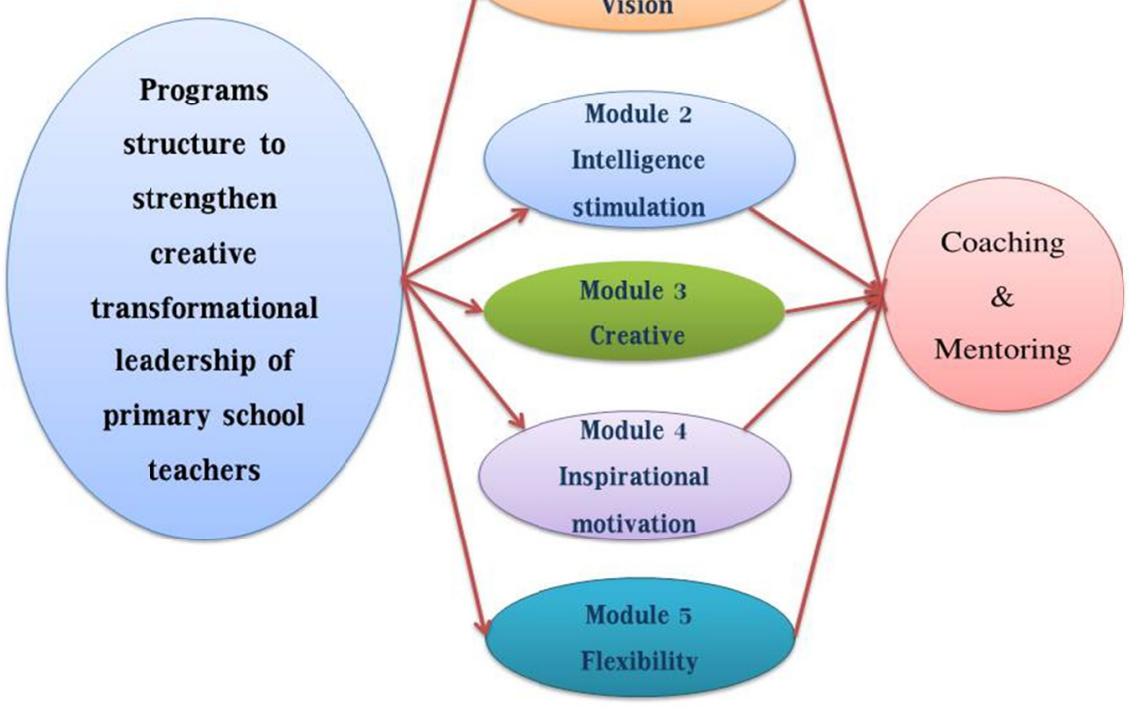

Figure 1. Programs structure to strengthen creative transformational leadership of primary school teachers

4) The effect of using the program to strengthen the creative transformational leadership of primary school teachers will now be described. Before using the program, we found the leadership assessment level was moderate $(\bar{X}=2.66)$ compared to post-program use, when this level was at high level $(\bar{X}=4.38)$. When we compared creative transformational leadership of primary teachers between after using the program and the follow-up period, it was apparent that the follow-up assessment was higher $(\bar{X}=4.39)$. We measured the satisfaction of users on the program to strengthen leadership, and this revealed that all dimensions were at high level $(\bar{X}=4.25)$.

\section{Discussion}

In our study, we found 5 elements and 16 indicators of creative transformational leadership of primary school teachers. Vision elements had 3 indicators, intellectual stimulation elements had 3 indicators, creative elements had 4 indicators, inspirational motivation elements had 3 indicators, and flexibility elements had 3 indicators. The result is consistent with the reviewed concept and theory both inside and outside Thailand. The result is also consistent with Rafferty \& Griffin (2004). That said elements of transformational leadership consist of: Vision that represents the ideal picture in the future based on the organizational norm. Vision is essential for all leaders to have in order to create prestige for themselves. The next element is intellectual communication that is transmitting positive information about the organization for purposes of increasing motivation and confidence to others. Intellectual stimulation is the next element, and is the driving force that enables followers to recognize problems and solve them in new and creative ways. The final element is personal recognition for the person who achieves the target of work. It is an award by situation that is an element of leadership exchange. This finding is similar to many others, such as in Parker and Begnaud (2004). They conclude in their book "Developing Creative Leadership" that the characteristics of creative leadership include vision, flexibility and problemsolving ability. Julsuwan, (2011) who conducted the research on the development of leadership change on management support institutions of higher education of government, wrote primarily of five elements: understanding change, idealized influence, inspirational motivation, intellectual stimulation, and relationships. Charuangdet, (2012) developed the model of transformational leadership of school administrators under the Office of Basic Education Commission and found five potential elements: understanding change, idealized influence, inspirational motivation, intellectual stimulation, and relationships. Reported also is how to develop leadership changes via five methods: training by lecture, case studies, brainstorming sessions, and role-play management games. The study shows cased the development principle for leader and was pilot tested.

The results of the study of the current and the desirable situations of creative transformational leadership of 
primary school teachers showed in practice level every dimension and at overall high level. This finding may be explained by the following reason.

Teachers are considered as primary professionals and as being a core sector to change a knowledge-based society. Without teachers and their high potential, society would be shaped in the future differently from the present, or indeed become an undesirable society. Collaboration, shared leadership, and collective responsibility are requirements of teachers. These elements are needed support to make clear understanding in belief, mutual norm, and performance of leadership within the context of structural change.

This finding is consistent with other concepts and studies such as when Fullan (2006) introduced the leadership characteristics of change as being: 1) inspiration builder, in that the leader should be able to inspire members on their vision, target set-up and mutual mission. 2) influence people to come along and join in the work to build a network of support. 3) provide improvement for others, understand weaknesses and strengths of others and have creative response-skills. 4) be a change catalyst for problem solving, sensitive to obstacles, and be able to overcome hindrances. 5) in terms of conflict management, leaders should handle the conflict well and dare to confront and manage conflict. 6) in terms of building bonds, leaders are needed to understand the differences of people. 7) capability in terms of teamwork and collaboration. Ratchapat, (2011) found that vision and the self-confidence to improve oneself and being a leader were the leadership indicators among primary school teachers.

The need to strengthen the creative transformative leadership of primary school teachers started with coaching technique, followed by mentoring. Coaching is the method to develop the potential of primary school teaching work. It focuses on the work-targeted orientation and takes existing knowledge into practice. While mentoring is a way of helping from experienced teachers to those with less experience regarding both professional and daily life in terms of meeting communal goals. Coaching and mentoring can be used with teachers in small groups and individually.

Consistent with the research of Thurston, Navarrete and Miller (2009) who conducted a ten-year study of the mentor to develop the new teacher program in the college of Kansas state university, this program has been designed by educational experts. It is planned for operations and implementation and evaluation every year. The results showed that the administrators of the university were aware of many things, such as finance, learning, staff and morale. The mentoring system for new teachers had succeeded, had cost effectiveness, promoted learning, increased morale and prevented the problems of work in the university. The mentor system with high efficiency brought people into the profession and benefits to the whole group, and with no waste of time to develop those talents.

The indicators and their elements that were constructed in this study are similar to Phucharoen's (2010) study that created and developed the pattern of leadership for school administrators who worked under the Office of Basic Education Commission. It concluded that the model developed for leadership of school administrators is composed of four parts; 1) concepts, 2) general purpose, 3) development process which consisted of five stages: (1) preparation stage (2) pre-assessment before development (3) development (4) evaluation of the development, (5) the development stage to apply 4) guidelines to use the development.

We tested knowledge of enhancing the creative transformative leadership of primary school teachers. The pre-test score was averaged at 12.82 of 30 ( $42.74 \%$ of total) compared to post-test score with 23 points ( $76.66 \%$ of total). All teachers passed the criteria score which was at least $60 \%$ of total score. The result affected the effectiveness of the program. This is similar to Chansiri (2008) who conducted a study on core-competencies development of supportive administrators in public universities. It concluded that a self-assessment and assessment by supervisors and subordinates before development in overall score level of competencies was high. However, comparison with post-development was lower significantly at $\mathrm{p}$-value $=0.01$.

The effect of using the program to strengthen creative transformational leadership of primary school teachers will now be described. Before using the program, we found the leadership assessment level was moderate compared to post-use which was at high level and subsequently highest at follow-up period. This is as compared with Wannakam (2010) who conducted the study for development of professional competencies of administrators who worked in small schools under the Office of Basic Education Commission. It revealed that before the development, the high competencies were moral and ethical leadership, being a good model and followed by a moral and ethical build up for staff. While after development the high competencies were organization set up, administration structure, and teacher task, followed by moral and ethical leadership, being a good model. 
The satisfaction of users on the program to strengthen leadership was in all respects at high level. This positive finding may be because the primary school teachers had opportunities for participation during the development program. Our result is similar to the study of Puangnil (2012), which reported that teachers were satisfied with leadership when conducting strategic management leadership for administrators. Chansiri, (2008) developed core competencies for supportive management of administrators. The participants who joined this development said they appreciated the program overall, and responded assessment was at the highest level for teamwork.

\section{Conclusions and Recommendations}

1) For primary school

- Primary school teachers who join the program must realize the importance of developing a program for strengthening the creative transformational leadership of primary school teachers. They must set aside time to develop the program in accordance with the model developed for each model. The developmental program is ongoing and systematic in manner. So it should support the strengthening of leadership. The promotion support has been developed in many forms including visits, training sessions, seminars, and study, and so on.

- Strengthening the leadership of creative teachers should take the form of professional development and integration of a diverse mix of development. As a form of documentation, documentation development, forms, orientation, forms of self-study, a form for intensive training, a form for searching, a form for study groups, a form for observation and assessment, forms for the improvement and development of a mentor, developmental model form or forms, and so on.

- To evaluate enhancing the creative leadership of teachers.

2) For Primary Education Service Area Office

- Office of Teacher Education Area should supervise and monitor changes to strengthen the leadership of creative teachers. According to the program, the results reinforce the importance of transformational leadership for creative teachers.

- The lecturer should have knowledge, experience, or expertise on the issues of training and enhancing the creative leadership of a teacher education program.

3) For Office of the Basic Education Commission.

- The Office of the Basic Education Commission should strengthen the Creative Leadership of Teachers Program to guide the development.

- The Office of the Basic Education Commission should provide support and resources for use in enhancing the Creative Leadership of Teachers Program.

- The Bureau of Personnel Administration Development and legal Affairs should strengthen the creative leadership program for development of teachers in Thailand.

\section{Recommendations for Further Research}

1) There should be a study on strengthening the creative leadership of teachers in other institutes.

2) There should be a study on strengthening the leadership of creative teachers in other formats.

3) There should be a study on leadership developmental models in the system, coupled with a model that focuses on offering leadership development methods, training and development.

\section{References}

Certo, S. C., \& Certo, S. T. (2006). Modern Management (10th ed.). New Jersey: Pearson Prentice Hall.

Chansiri, W. (2008). The development of the core competencies of supportive executive in public universities (Education doctoral thesis, Administration and Development Studies, Mahasarakrm University).

Chareonwongsak, K. (2007). Super leadership. Bangkok: Success Media.

Charuangdet, L. (2012). Transformational Leadership Development Model of School Administrators under the Office of Basic Education (Education Ph.D, Administration and Development Studies Faculty of Education University).

Dunham-Taylor, J. (2000). Nurse Executive Transformational Leadership Found in Participation Organization. Journal of Nursing Administration, 30(5), 241-250. https://doi.org/10.1097/00005110-200005000-00005

Fullan, M. G. (2006). The Future of Educational Change: System Thinkers in Action. Journal of Educational 
Change, 7(3), 113-122. https://doi.org/10.1007/s10833-006-9003-9

Goodson, I., \& Hargreaves, A. (2005). Series editors'preface. In A. Harris, \& D. Muijs (Eds.), Improving schools through teacher leadership. New York: Open University Press

Greenberg, J., \& Baron, R. A. (2002). Behavior In organizations: Understanding and Managing the Human Side of Work. New Jersey: Prentice Hall.

Gronn, P. (2008). The Future of Distributed Leadership. Journal of Educational Administration, 46(2), 141-158. https://doi.org/10.1108/09578230810863235

Harris, A., \& Lambert, L. (2003). Building Leadership Capacity for School Improvement. London: Open University Press.

Hedberg, B. (1981). How Organizations Learn and Unlearn. In P. C. Nystrom (Eds.), Handbook of Organizational Design, Oxford: Oxford University Press.

Julsuwan, S. (2011). Development of supportive of the leadership on management change in higher educational institutions (Education Ph.D., Administration and Development Studies, Faculty of Education, Mahasarakharm University).

McCutcheon, A. (2005). Leadership Style, Span of Control and Performance. Retrieved from https://www.amy.McCutcheona@smh.utoronto.on.ca

Office of the Education Council. (2009). Strategic development and production capacity of the country. Education reform in the second century 2009-2018. Retrieved from http: //www.onec.go

Parker, J. P., \& Begnaud, L. G. (2004). Developing Creative Leadership. Portsmouth, NH.: Teacher Ideas Pr.

Phucharoen, S (2010). Creating a leadership development model of school administrators Under the Office of Basic Education Commssion (Education Ph.D. in educational administration, Nakhon Ratchasima Rajabhat University.

Puangnil, T. (2012). Strategic leadership development program. For the management of basic education (Doctor of Philosophy Department of Management Studies).

Rafferty, A. E., \& Griffin, M. A. (2004). Dimensions of Transformational Leadership: Conceptual and Empirical Extensions. The Leadership Quarterly, 15(3), 329-354. https://doi.org/10.1016/j.leaqua.2004.02.009

Ratchapat, A. (2011). Development leadership Indicators of teachers in basic education (Phd thesis, Department of Management Studies, Khon Khean University).

Sinlarat, P. (2008). Teacher professional development tools and concepts. Bangkok. Chulalongkorn University printing.

Spillane, J. P., Halverson, R., \& Diamond, J. B. (2001). Investigating School Leadership Practice: A Distributed Perspective. Educational Research, 30(3), 23-28. https://doi.org/10.3102/0013189x030003023

Thurston, L. P., Navarrete, L., \& Miller, (2009) A Ten Year Faculty Mentoring Program: Administrator, Mentor, and Mentee Perspectives. The International Journal of Learning, 16(4), 401-415. https://doi.org/10.18848/1447-9494/cgp/v16i04/46208

Wannakam, V, (2010). The development of professional competencies of school administrators in small department of basic education (Educational Leadership Doctoral degree programs in educational administration, Nakhon Ratchasima Rajabhat University).

\section{Copyrights}

Copyright for this article is retained by the author(s), with first publication rights granted to the journal.

This is an open-access article distributed under the terms and conditions of the Creative Commons Attribution license (http://creativecommons.org/licenses/by/4.0/). 